\title{
A Comparative Study to Evaluate the Efficacy of Oral Lactoferrin Fortified Bovine Colostrum with Oral Iron in the Treatment of Iron Deficiency Anemia
}

\author{
Taruni Ramakrishnan ${ }^{1}$, Malar Sivaraman ${ }^{1}$, Trayambak Dutta $^{2 *}$, Dhanasekar K Ramasamy²
}

\begin{abstract}
Context: Oral Ferrous Sulfate (OFS) is associated with 25 to $40 \%$ incidence of adverse drug reactions (ADRs) in the treatment of Iron Deficiency Anemia (IDA). Can there be a suitable alternative treatment for IDA? Aim: To compare the efficacy of oral lactoferrin fortified bovine colostrum (OLFBC), and in combination with Oral Ferrous Sulfate (OFS) in the treatment of IDA. Settings and Design: Prospective randomized open-label. Material and Methods: Sixty eight anemic women were recruited in three parallel arms. The control arm was given OFS $333 \mathrm{mg}$ (containing $100 \mathrm{mg}$ elemental iron) once-daily, the study arm received OLFBC $2 \mathrm{~g}$ once-daily, while the combination arm received both for 30 days. Statistical Analysis Used: Baseline and post-therapy Haemoglobin $(\mathrm{Hb})$ and iron parameters were assessed and analyzed using student's paired $t$-test, ANOVA and Wilcoxon signed rank test. Results: A significant improvement in $\mathrm{Hb}$ and iron parameters was noted from baseline to post-therapy in the arms that received OLFBC and this treatment was associated with fewer ADRs. The ADRs were comparatively lesser in the arms that received OLFBC than the OFS arm. Conclusion: OLFBC is a safe and efficacious treatment modality for IDA compared to OFS.
\end{abstract}

Key words: Iron deficiency anemia, Lactoferrin fortified bovine colostrum, Ferrous sulphate, Serum ferritin, TIBC, Haemoglobin.

Key messages: OLFBC is a better alternative than OFS in the treatment of IDA.

\section{INTRODUCTION}

Iron deficiency (ID) affects more than 2 billion people globally, with greater prevalence in women and children. OFS is most commonly prescribed drug for treating ID; however, it has been associated with 25$40 \%$ incidence of adverse drug reactions. Moreover, it has a variable bioavailability, thus stressing a need for better oral formulations. Lactoferrin is a glycoprotein structurally resembling transferrin plays a role in iron absorption. Iron is an essential element that the body needs for normal tissue oxygenation. Iron deficiency represents the most common nutritional deficiency. While more than 2 billion people worldwide are known to be iron-deficient. ${ }^{1}$ In India, the prevalence of iron deficiency anemia is nearly $74.3 \%$. Women and children are the most commonly affected. ${ }^{2}$ Iron absorption and metabolism is a complex, tightly regulated mechanism in humans. Humans ingest nearly $12-18 \mathrm{mg} /$ day of dietary iron; of this, only 1-2 $\mathrm{mg}$ is absorbed. Adult men and non-menstruating women require $13 \mathrm{mg} / \mathrm{kg} /$ day of iron while menstruating women require $21 \mathrm{mg} / \mathrm{kg} /$ day. In the last two trimesters of pregnancy, iron requirement may go up to $80 \mathrm{mg} / \mathrm{kg} /$ day. ${ }^{3}$ Non-heme iron is obtained from plant-based foods including cereals, legumes, pulses, fruits and vegetables. Non-heme iron requires acid digestion and is dependent on dietary enhancers and inhibitors. On the contrary, heme iron is minimally affected by dietary factors. ${ }^{4}$ Iron absorption occurs in the duodenum and upper jejunum. Two transport proteins, divalent metal transporter 1 (DMT-1) and heme carrier protein ( $\mathrm{HCP} 1)$ have been implicated in the transport of iron to the cytosol of the enterocyte. Iron in the enterocyte is either stored as ferritin or exported to the blood and is carried to tissues by transferrin. An iron transporter, ferroportin, assists the export of iron from the enterocytes. ${ }^{5}$ Ferric iron in the plasma is scavenged by transferrin (Tf) and is transported to tissues that either utilize or store the iron. ${ }^{6}$ The absorption of iron accounts for a mere fraction of the iron in the body with over $90 \%$ arising from the recycling of senescent red blood cells (RBCs). When there is a deficiency of iron, the body increases its iron absorption by 3 to 5 folds. In contrast, when there is an iron overloaded state, the body adopts the 'mucosal block phenomena' where iron bound to apo-ferritin in an enterocyte is shed off from the gastrointestinal tract (GIT) along with the gastric epithelial cells. When there is excess of iron, ferroportin fails to transport absorbed iron out of the enterocytes. ${ }^{7}$ On the other hand, increased IL-6 is also known to directly cause the down-regulation of ferroportin mRNA expression, thus resulting in

Article Available online

http://www.ijmedph.org/v8/i2

Copyright

(C) 2018 Phcog.Net. This is an openaccess article distributed under the terms of the Creative Commons Attribution 4.0 International license.

Cite this article : Taruni R, Sivaraman M, Dutta T, Dhanasekar KR. A Comparative Study to Evaluate the Efficacy of Oral Lactoferrin Fortified Bovine Colostrum with Oral Iron in the Treatment of Iron Deficiency Anemia. Int J Med Public Health. 2018;8(2):65-70. 
decreased iron absorption. ${ }^{8}$ Iron, being a constituent of various proteins and enzymes, is crucial to an array of biological processes ranging from tissue oxygenation, energy metabolism to bactericidal actions of the immune system. ID occurs when the absorption of iron is insufficient to meet the demands of the body. Mild-to-moderate forms of iron deficits manifest as functional tissue impairment even in the absence of anemia. The condition, in pregnant women, is linked with increased morbidities and mortality during the antenatal period and poor outcomes. ${ }^{9}$ Children with iron deficiency anemia manifest psychomotor developmental delays. ${ }^{1}$ It thus becomes increasingly essential to correct the deficiency in an individual. An individual is labeled anemic when the haemoglobin falls under 2 standard deviation (SD) of the mean hemoglobin of a population of same age, sex and altitude. The World Health Organization (WHO) has defined anemia as a hemoglobin value $<11 \mathrm{~g} / \mathrm{dL}$ (at sea level). ${ }^{10}$ The Indian Council of Medical Research (ICMR) has categorized the severity of IDA on the basis of hemoglobin levels as mild, moderate and severe. ${ }^{11}$ The treatment modalities available at present, including OFS and parenteral iron, are associated with many ADRs resulting in poor patient compliance and poor response to therapy..$^{10}$ Lactoferrin on the other hand is an iron binding glycoprotein which does not produce any ADRs. Lactoferrin is a glycoprotein found in colostrums that belongs to transferrin family. It is involved in absorption of iron from dietary sources. ${ }^{13}$ It thus appears that supplementing lactoferrin should increase iron absorption. Its efficacy in increasing iron parameters in pregnant women has been established in a few European studies. ${ }^{14-16}$ The highest concentration of lactoferrin is found in colostrum $(7 \mathrm{~g} / \mathrm{dL})$ followed by milk $(1 \mathrm{~g} / \mathrm{dL})$ where it is believed to be a major source of iron for infants. ${ }^{17}$ Lactoferrin is purified and isolated from human or cow's milk; however, recombinant lactoferrin is also available. Human milk contains more lactoferrin but iron extraction from bovine lactoferrin has been noted to be higher. ${ }^{13}$ Lactoferrin is known to play significant roles in iron absorption, immunity, inflammation, tumor growth, myelin genesis and enzymatic activities.

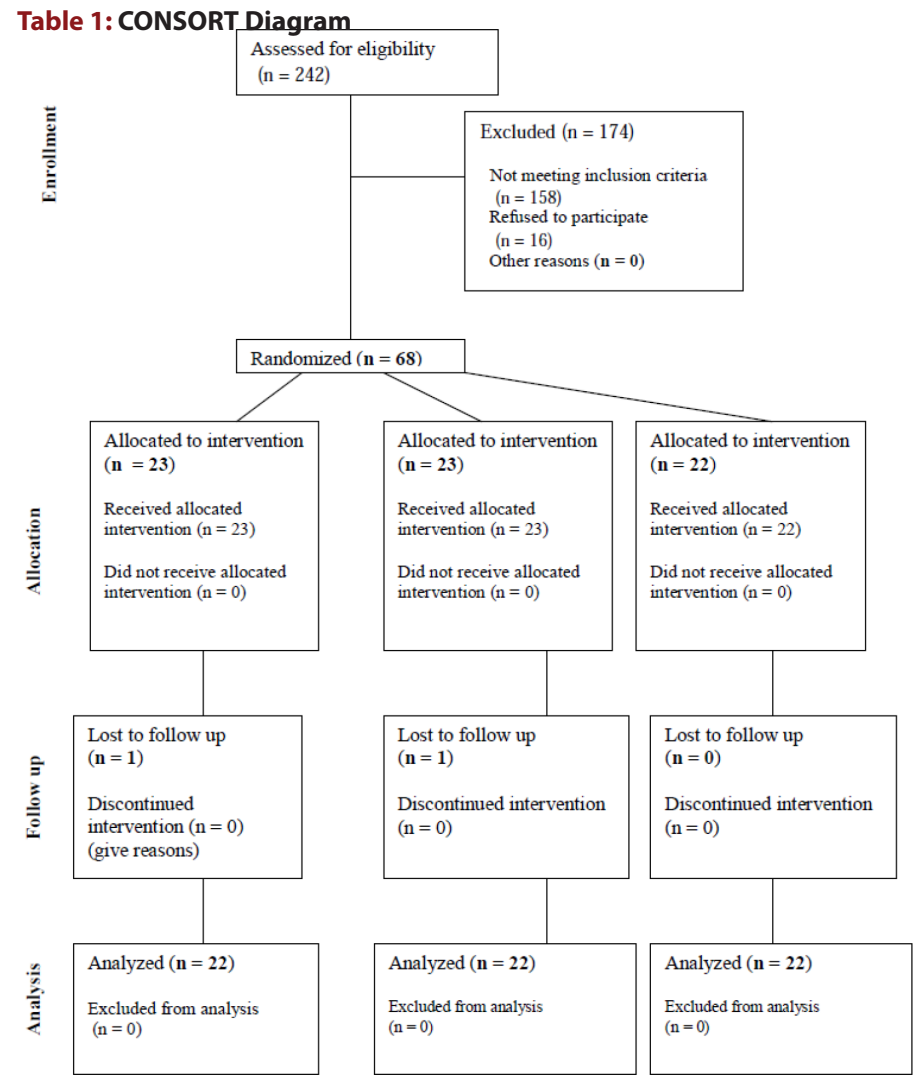

OLFBC is a nutritional supplement available in India that has high lactoferrin content. It has no unpleasant side effects and can therefore improve patient compliance and result in better therapeutic outcomes. A study was thus conducted to ascertain the efficacy of OLFBC in treating IDA in Indian women.

\section{MATERIALS AND METHODS}

Female patients within 18-21 years of age with clinically proven IDA satisfying the inclusion criteria were screened and recruited. This was followed by randomization and grouping and baseline investigations. A 30-day treatment regimen and analysis of post-therapy investigations was done, which evaluated the efficacy of the treatment given. The Institute Ethical Committee clearance was obtained before the study initiation. Results from a previous study conducted on Italian pregnant women was used to calculate sample size. A two-sided $t$-test helped detect superiority of OLFBC over OFS. A minimum sample size of 12 per group was required to have a $90 \%$ chance (alpha error of 0.05 ) of detecting an increase in $\mathrm{Hb}$ level to $11.5 \mathrm{~g} / \mathrm{dL}$ (SD of $0.6 \mathrm{~g} / \mathrm{dL}$ ) in the OFS group and $12.7 \mathrm{~g} / \mathrm{dL}$ (SD of $0.9 \mathrm{~g} / \mathrm{dL}$ ) in the experimental group. ${ }^{14}$ On adjustment for non-compliance in the OFS arm to $40 \%$, a sample size of 68 was arrived at. Written informed consent was obtained from those fulfilling the inclusion criteria and willing to participate in the study. A detailed history and clinical examination was performed on the participants. Venous blood was drawn for baseline assessment of iron parameters and other routine tests. The participants were randomized into $3 \mathrm{arms}$, using a computerized randomization chart. Numbered containers were used as a method of allocation concealment. The study drug was sealed in sequentially numbered identical containers according to the allocation sequence and being distributed as per the protocol into their respective groups. The control arm received OFS $333 \mathrm{mg}$ (100 mg elemental iron) once-daily empty stomach. The study arm received OLFBC $2 \mathrm{~g}$ oncedaily empty stomach and the third arm received both OFS and OLFBC (Table 1). Both supplements were administered orally for a period of 30 days. OLFBC was given as a powder and had to be reconstituted in 200 $\mathrm{mL}$ of potable water before consumption.

Patients with IDA and $\mathrm{Hb}$ levels between 8 and $11 \mathrm{mg} / \mathrm{dL}$ were included in the study. Known cases of anemia due to secondary causes such as infections, neoplasms, genetic diseases, hypochlorhydria or renal disease, presence of inflammation or infection detectable by a raised erythrocyte sedimentation rate (ESR) were excluded. Patients taking any medication that could interfere with iron absorption such as antacids/proton pump inhibitors (PPIs), patients on iron supplements or having a history of recent supplementation (over past 3 months) and patients having menorrhagia or a known source of bleeding (varices, ulcers, etc.) were also excluded from the study.

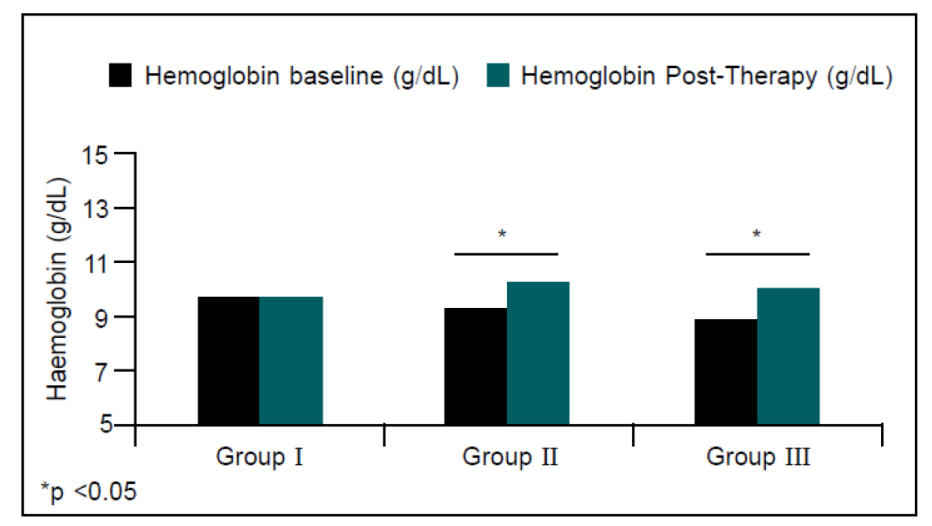

Figure 1: Mean $\mathrm{Hb}$ pre and post intervention amongst the three groups. 
Table 2: Group I (Ferrous Sulfate Arm) Paired $t$-Test

\begin{tabular}{ccccc} 
Change in parameter & Mean & \multicolumn{2}{c}{$95 \%$ Confidence interval } & P value \\
& & Lower & Upper & 0.717 \\
Hemoglobin & 0.028 & -0.12942 & 0.18542 & 0.753 \\
Serum ferritin & -0.71956 & -5.3926131 & 3.9534931 & 0.752 \\
Serum iron & 1.544 & -8.4068 & 11.4948 & 0.287 \\
TIBC & -16.8732 & -48.86705 & 15.12065 & 0.307 \\
UIBC & -18.4172 & -54.79935 & 17.96495 & 0.477 \\
TSAT & 0.79140 & -1.47008 & 3.05289 &
\end{tabular}

Table 3: Group II (Lactoferrin Fortified Bovine Colostrum Arm) Paired $t$-Test

\begin{tabular}{|c|c|c|c|c|}
\hline \multirow[t]{2}{*}{ Parameters } & \multirow[t]{2}{*}{ Mean } & \multicolumn{2}{|c|}{$95 \%$ Confidence interval } & \multirow[t]{2}{*}{$P$ value } \\
\hline & & Lower & Upper & \\
\hline Hemoglobin* & 0.9288 & 0.5634 & 1.2942 & $<0.01$ \\
\hline Serum ferritin & 0.701521 & -4.6488118 & 6.0518534 & 0.789 \\
\hline Serum iron* & 18.4952 & 4.40917 & 32.58123 & 0.012 \\
\hline TIBC $^{*}$ & -118.176 & -157.64586 & -78.70614 & $<0.01$ \\
\hline UIBC $^{*}$ & -136.671 & -185.53979 & -87.80261 & $<0.01$ \\
\hline TSAT $^{*}$ & 8.15946 & 3.67436 & 12.64456 & 0.01 \\
\hline
\end{tabular}

${ }^{*} \mathrm{p}<0.05$ is considered significant

Table 4: Group III (Combination Therapy Arm) Paired $t$-Test.

\begin{tabular}{ccccc} 
Parameters & Mean & \multicolumn{2}{c}{$95 \%$ Confidence interval } & P value \\
& & Lower & Upper & 0.001 \\
Hemoglobin & & 0.52544 & 1.59956 & 0.669 \\
Serum ferritin & 1.0625 & -11.9268783 & 18.0561283 & 0.011 \\
Serum iron & 3.064625 & 4.50649 & 30.20851 & 0.01 \\
TIBC $^{*}$ & 17.3575 & -153.66176 & -24.66449 & 0.004 \\
UIBC $^{*}$ & -89.1631 & -173.23954 & -39.80171 & 11.72011 \\
TSAT $^{*}$ & -106.521 & 3.66723 & & 0.01
\end{tabular}

A clinical assessment was performed after obtaining a detailed history. Eight milliliter ( $8 \mathrm{ml}$ ) of venous blood was collected from the subject under strict aseptic precautions for routine investigations including complete blood count (total count (TC), differential count (DC), ESR, Hb), peripheral smear, serum urea, serum creatinine, serum bilirubin, serum glutamic oxaloacetic transaminase/serum pyruvic transaminase (SGOT/ SGPT). Subjects' iron status was assessed by monitoring serum iron, serum ferritin, total iron-binding capacity (TIBC), serum transferrin saturation and unsaturated iron-binding capacity (UIBC). Statistical analysis was performed using SPSS version 17 software. Continuous variables were described as means along with their SDs, while discrete variables were expressed as frequencies and percentages. Within each group, the mean change in hemoglobin and iron parameters from baseline to post-therapy was assessed using student's paired $t$-test. A one way analysis of variance (ANOVA) helped assess the significance of change in parameters between the three groups. A nonparametric Wilcoxon signed rank test was used to analyze serum ferritin.

\section{RESULTS}

Two hundred and forty two patients were screened for the clinical presence of conjunctival pallor to establish the diagnosis of IDA on the basis of signs and symptoms. Eighty four of which were shortlisted and complete blood count $(\mathrm{CBC})$ and peripheral smear were carried out on them to further substantiate the diagnosis of IDA. Sixteen of these subjects did not fulfill the inclusion criteria and were excluded from the study. The 68 students recruited into the study were randomly allocated to three groups (Table 1). All the participants of the study belonged to the female gender with mean age of $19.15 \pm 0.685$ years (range 18-21 years). There was no significant variation in age within group or between the three groups. The baseline and post-treatment values of TC, DC, ESR, SGOT, SGPT, serum urea, serum creatinine and serum bilirubin were normal in all the subjects. Participants in Group I exhibited a mean increase in $\mathrm{Hb}$ of $0.028 \mathrm{~g} / \mathrm{dL}$, which was not statistically significant $(\mathrm{p}=0.717)$ (Table 2). Participants in Group II showed a significant increase in their $\mathrm{Hb}$ levels post-therapy with a mean increase in $\mathrm{Hb}$ of $0.9288 \mathrm{~g} / \mathrm{dL}(\mathrm{p}<0.001)$ (Table 3). Participants in Group III also showed a 
Ferritin Baseline $(\mathrm{mcg} / \mathrm{dL})$

Ferritin Post-intervention (mcg/dL)

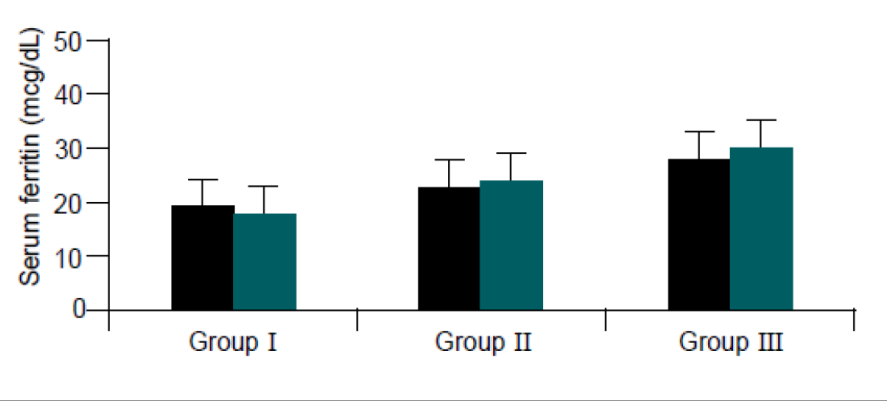

Figure 2: Serum ferritin pre and post intervention amongst the three groups.

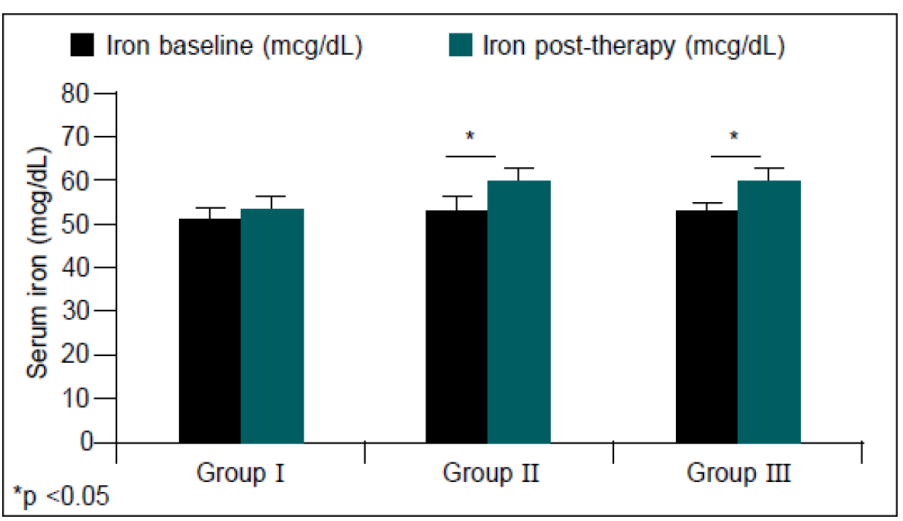

Figure 3: Serum Iron pre and post intervention amongst the three groups.

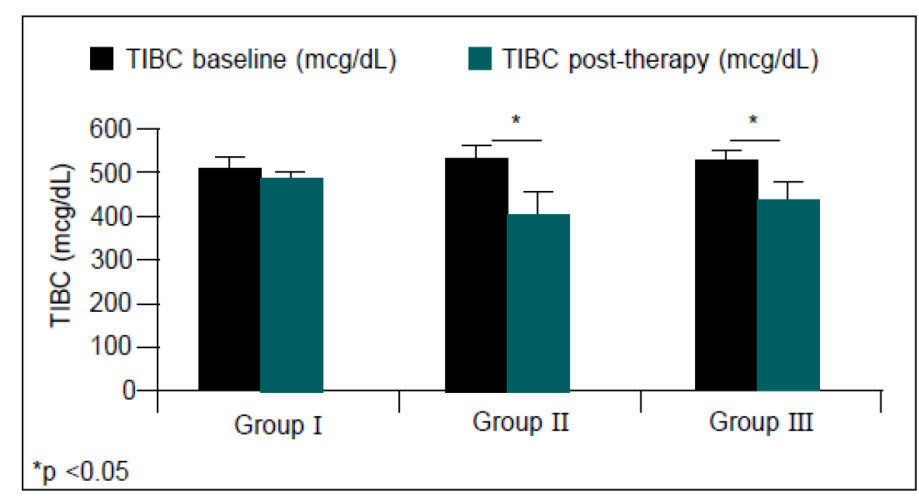

Figure 4: Serum TIBC pre and post intervention amongst the three groups.

significant increase in their hemoglobin levels post-therapy with a mean increase of $1.0625 \mathrm{~g} / \mathrm{dL}(\mathrm{p}=0.001)$ (Table 4, Figure 1), There was no significant difference in baseline values between the three groups. However, a significant difference in the rise in $\mathrm{Hb}$ values in Group II and III ( $\mathrm{p}<0.001$ and 0.001 , respectively) was evident in comparison to Group I ( $p=0.717)$. There was no significant difference in the rise in $\mathrm{Hb}$ between Group II and Group III ( $\mathrm{p}=0.877)$. A Wilcoxon signed-rank test demonstrated a decrease in ferritin stores in Group I that was not statistically significant $(\mathrm{p}=0.420, \mathrm{z}=0.807)$. Participants of Group II

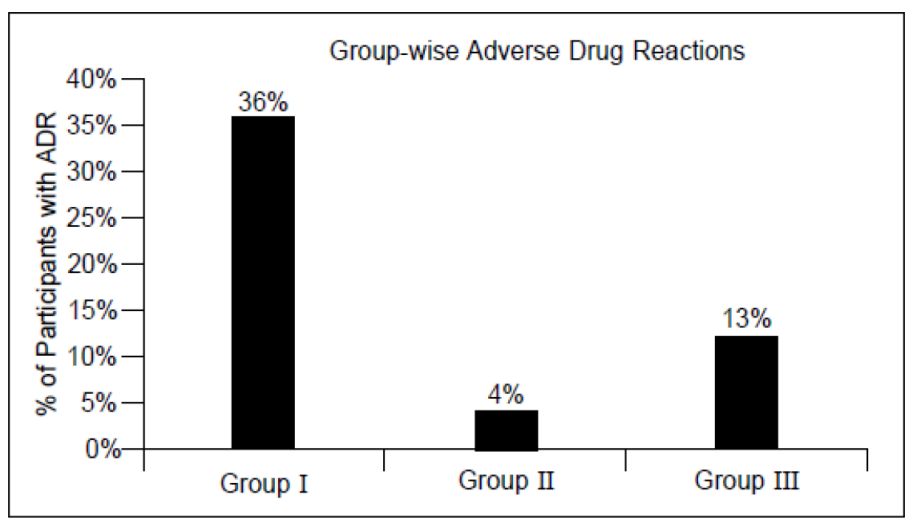

Figure 5: ADRs noted amongst the three groups.

demonstrated an increase in ferritin levels post-therapy, which was also statistically insignificant ( $\mathrm{p}=0.819, \mathrm{z}=0.229$ ). Participants of Group III demonstrated an increase in ferritin levels post-therapy which was again insignificant ( $p=0.717, z=0.362)$, (Figure 2). Participants in Group I had a mean increase in SIC of $1.544 \mu \mathrm{g} / \mathrm{dL}$, which was not statistically significant $(\mathrm{p}=0.752)$. Participants in Group II showed a significant increase in their SIC post-therapy with a mean increase of $18.4952 \mu \mathrm{g} / \mathrm{dL}$ $(\mathrm{p}=0.012)$. Participants in Group III also showed a significant increase in their SIC values post-therapy with a mean increase of $17.3575 \mu \mathrm{g} / \mathrm{dL}$ $(\mathrm{p}=0.011)$, (Figure 3). There was no significant difference in the rise in SIC levels between the three groups $(\mathrm{p}=0.095,0.198,0.991)$. Participants in Group I exhibited a mean decrease in

TIBC of $16.8732 \mu \mathrm{g} / \mathrm{dL}$ that was statistically insignificant $(\mathrm{p}=0.287)$. Participants in Group II showed a significant decrease in TIBC values post-therapy with a mean reduction of $118.176 \mu \mathrm{g} / \mathrm{dL}(\mathrm{p}<0.001)$. Participants in Group III also showed a significant decrease in their TIBC values post-therapy with a mean decrease of $89.16313 \mu \mathrm{g} / \mathrm{dL}$ $(\mathrm{p}=0.01)$, (Figure 4$)$. Post-therapy TIBC values of Group II and III were significantly different from that of Group I ( $p<0.01, p=0.01$, respectively). There was no significant difference in the post-therapy TIBC values between Group II and III ( $\mathrm{p}=0.904)$. On conducting a difference in difference analysis, the fall in TIBC values of Group II was significantly more than that in Group I $(p=0.001)$. There was no significant difference in change in TIBC values observed between Group I and III $(\mathrm{p}=0.057)$ or between Group II and III $(\mathrm{p}=0.616)$. Participants in Group I had a mean decrease in UIBC of $18.4172 \mu \mathrm{g} / \mathrm{dL}$, which was statistically insignificant $(\mathrm{p}=0.307)$. Participants in Group II showed a significant decrease in UIBC values post-therapy with a mean decrease in UIBC of $136.6712 \mu \mathrm{g} / \mathrm{dL}$ ( $\mathrm{p}<0.001$ ). Participants in Group III also exhibited a significant decrease in UIBC values post-therapy with a mean decrease of $106.521 \mu \mathrm{g} / \mathrm{dL}(\mathrm{p}=0.004)$. Post-therapy, the UIBC values of Group II and III were significantly different from that of Group I ( $\mathrm{p}<0.01, \mathrm{p}=0.01$, respectively). However, there was no significant difference in the post-therapy UIBC values between Group II and III $(p=0.844)$. A difference in difference analysis revealed that the fall in UIBC values of Group II and III was significantly more than that observed in Group I ( $p=0.001,0.039$, respectively). There was no significant difference in change in UIBC values observed between Group II and III ( $\mathrm{p}=0.668)$. Participants in Group I showed an insignificant mean increase TSAT of $0.79140 \%(\mathrm{p}=0.477)$. Participants in Group II showed a significant increase in TSAT values post-therapy with a mean increase of $8.15946 \%$ ( $p=0.001)$. Participants in Group III also showed a significant increase in their TSAT values post-therapy with a mean increase in TSAT of $7.69367 \%(p=0.001)$. Post-therapy TSAT values of Group II 
were significantly different from that of Group I ( $\mathrm{p}=0.017)$. There was no significant difference in the post-therapy TSAT values between Group II and III or between Group I and III ( $\mathrm{p}=0.951,0.078$, respectively). When a difference in difference analysis was conducted, the rise in TSAT values of Group II and III were significantly more than that observed in Group I ( $\mathrm{p}=0.008,0.03$, respectively). There was no significant difference in change in TSAT values observed between Group II and III ( $p=0.983)$. Twelve participants reported adverse effects to their medication. Most of the adverse effects were reported on questioning the participants at the end of the study period. The only exception was a single case of gastritis who was treated with H2-blocker during the study period. Figure 5 demonstrates the group-wise split up. Gastritis, constipation, nausea, vomiting and loose stools were the side effects noted in the participants during the study duration. Sixty-six of the 68 recruited participants completed the study. The two drop outs belonged to Group III. One was diagnosed with infective hepatitis and was not available for follow-up. The other drop out resorted to intravenous iron instead of taking her oral medications and voluntarily dropped out of the study. The compliance in Group I was found to be $44 \%$. The compliance in Group II and III was $94 \%$ each.

\section{DISCUSSION}

OFS is the most extensively prescribed drug for treating IDA but unfortunately it is associated with poor compliance, gastrointestinal ADRs and variable bioavailability. This calls for a better oral formulation in the treatment of IDA. Lactoferrin plays an important role in iron absorption. Studies conducted in Italian pregnant women and Japanese athletes have demonstrated the beneficial effects of bovine lactoferrin in treating IDA. A randomized, active controlled, open-labeled, 3armed parallel study was thus designed to compare the efficacy of OLFBC (as single agent and in combination with OFS) with OFS in the management of IDA. The prevalence of anemia in our study cohort was found to be $35 \%$. This is comparable to previous studies conducted in India, that have shown nearly $40 \%$ of asymptomatic patients in their study to have biochemical evidence of IDA. ${ }^{18,19}$ Our study exhibited significant improvement in $\mathrm{Hb}$ levels and most of the iron parameters in participants of Group II (OLFBC) and Group III (combination therapy arm) compared to Group I (OFS arm). The significant increase in $\mathrm{Hb}$ and SIC values post-therapy in both Group II and III $(p<0.05)$ is in accordance with study by Paesano et al, 2006 conducted among pregnant women in Italy which reported a mean increase in $\mathrm{Hb}$ of $1.5 \mathrm{~g} / \mathrm{dL}$ and a mean increase in SIC of $54.2 \mu \mathrm{g} / \mathrm{Dl} .{ }^{15}$ In the present study, a mean rise in $\mathrm{Hb}$ of $0.9288 \mathrm{~g} / \mathrm{dL}$ and a mean rise in SIC of $18.4952 \mu \mathrm{g} / \mathrm{dL}$ was noted in Group II. Group III exhibited a mean rise in $\mathrm{Hb}$ of $1.0625 \mathrm{~g} / \mathrm{dL}$ and mean rise in SIC of $17.3575 \mu \mathrm{g} / \mathrm{dL}$. The mean rise in $\mathrm{Hb}$ and SIC in our study is lower than the Paesano et al, 2006 study, which may be explained by the higher dose of lactoferrin employed in the later study. Although the rise in $\mathrm{Hb}$ and SIC values are lower in this study, the rise observed in Group II and III are both clinically and statistically significant $(\mathrm{p}<0.05)$. No improvement in $\mathrm{Hb}$ levels and other iron parameters were noted in OFS arm. This is in accordance with a study conducted in Italian pregnant women in 2010 who were prescribed $156 \mathrm{mg}$ of elemental iron for 30 days. This study documented a parallel fall in serum Interleukin-6 levels leading to hepcidin-mediated down regulation of ferroportin resulting in decreased enteral iron absorption. ${ }^{14}$ The rise in $\mathrm{Hb}$ level $(0.028 \mathrm{~g} / \mathrm{dL})$ in Group I of our study is much less than a previous study $(1.05 \mathrm{~g} / \mathrm{dL})$ conducted among pregnant women in India in the Guntur district by Chandrakala Kambar et al. ${ }^{20}$ This could be attributed to better compliance and longer duration of therapy amongst the pregnant women. The marginal rise in $\mathrm{Hb}(0.028 \mathrm{~g} / \mathrm{dL}, \mathrm{p}=0.717)$ and SIC $(1.544 \mu \mathrm{g} / \mathrm{dL}$, $\mathrm{p}=0.752)$ in Group I was significantly lower compared to Group II and
III ( $\mathrm{p}<0.05$ ), thus highlighting that OLFBC increased SIC thereby improving $\mathrm{Hb}$ levels.

The insignificant change in ferritin levels in all the three groups may be due to the fact that at least a 3-month course of therapy is required for restoring iron stores in the body. ${ }^{21}$ Ferritin levels have been noted to rise as early as 2 weeks in an ICMR study conducted by Kriplani et al, where the route of administration was intravenous which has a higher bioavailability than the oral route. ${ }^{11}$ Another study conducted by Natsue Koikawa et al amongst Japanese runners, comparing efficacy of lactoferrin and OFS reported a decrease in ferritin stores in both the arms after 8 weeks of therapy. ${ }^{22}$ Since there is an inversely proportionally relationship between serum iron concentration (SIC) and TIBC/UIBC hence only a marginal fall was noted amongst these parameters in the OFS arm of our study. ${ }^{23}$ In Group II and Group III of our study a significant rise in transferrin saturation $(\mathrm{p}<0.05)$ with an increase in SIC was noted. This significant improvement is contrary to that observed in Maccio et al, (2010) study where cancer patients with anemia of chronic disease were administered lactoferrin along with erythropoietin. ${ }^{24}$ Hence, the beneficial effect of lactoferrin, seen in cases of nutritional ID, does not extrapolate to anemia of chronic disease. Since there was no statistically significant difference in the iron parameters and $\mathrm{Hb}$ levels in post therapy compared to baseline, it can be quoted that there are no hematological benefits of combining OFS with OLFBC. The subjects administered with OLFBC reported fewer adverse effects $(4 \%, 13 \%)$ than those on OFS $(36 \%)$. Toliken et al, (2015) reported similar adverse effects with OFS. ${ }^{25}$

In conclusion our study demonstrates significant improvement in iron parameters and $\mathrm{Hb}$ levels in patients in OLFBC group as compared to OFS group. Subjects receiving OLFBC reported fewer adverse effects and adhered to their treatment regimen more faithfully compared to those on the OFS regimen. No significant improvement in iron and hematological parameters was noted on addition of OFS to OLFBC, though the combination demonstrated lower incidence of ADRs.

\section{CONCLUSION}

It can be concluded that OLFBC is more efficacious in treating IDA as compared to OFS with additional clinical benefits of fewer ADRs and better patient compliance.

\section{ACKNOWLEDGEMENT}

We sincerely thank Mrs.Edwin Nirmala, Principal of School of Nursing, Government Kilpauk Medical College, for her valued contribution in the patient screening and recruitment process.

\section{CONFLICT OF INTEREST}

The authors declare no conflcit of interest.

\section{ABBREVIATIONS}

OFS: Oral Ferrous Sulfate, IDA: Iron Deficiency Anemia, OLFBC: Oral Lactoferrin Fortified Bovine Colostrum, ID: Iron Deficiency, DMT-1: Divalent Metal Transporter 1, HCP1: Heme Carrier Protein, GIT: Gastrointestinal Tract, RBCs: Red Blood Counts, Tf: Transferrin, WHO: World Health Organization, SD: Standard Deviation, ICMR: The Indian Council of Medical Research, ESR: Erythrocyte Sedimentation Rate, PPIs: Protein Pump Inhibitors, TC: Total Count, DC: Differential Count, Hb: Haemoglobin, SGOT: Serum Oxaloacetic Transaminase, SGPT: Serum Pyruvic Transaminase, TIBC: Total Iron Binding Capacity, UIBC: Unsaturated Iron Binding Capacity, ANOVA: Analysis of Variance, CBC: Complete Blood Count, SIC: Serum Iron Concentration 


\section{SUMMARY}

OLFBC is a better alternative to OFS in the treatment of IDA both in terms of safety and efficacy.

\section{REFERENCES}

1. Camaschella C. Iron deficiency: New insights into diagnosis and treatment. Hematology Am Soc Hematol Educ Program. 2015;2015(1):8-13.

2. Ministry of Health and Family Welfare Government of India. Guidelines for Control of Iron Deficiency Anaemia. Available from: http://www.pbnrhm.org/ docs/iron_plus_guidelines.pdf, last accessed on 30/04/2018.

3. Abbaspour N, Hurrell R, Kelishadi R. Review on iron and its importance for human health. J Res Med Sci. 2014;19(2):164-74.

4. Lim KH, Riddell LJ, Nowson CA, Booth AO, Szymlek-Gay EA. Iron and zinc nutrition in the economically developed world: A review. Nutrients. 2013;5(8):3184-11.

5. Knutson MD. Iron transport proteins: Gateways of cellular and systemic iron homeostasis. J Biol Chem. 2017;292(31):12735-43

6. Cassat JE, Skaar EP. Iron in infection and immunity. Cell Host Microbe. 2013;13(5):509-19.

7. Drakesmith $\mathrm{H}$, Nemeth $\mathrm{E}$, Ganz $\mathrm{T}$. Ironing out Ferroportin. Cell Metab. 2015;22(5):777-87.

8. Langer $A L$, Ginzburg $Y Z$. Role of hepcidin-ferroportin axis in the pathophysiology, diagnosis, and treatment of anemia of chronic inflammation. Hemodial Int. 2017;21(S1):S37-46

9. Tiwari M, Kotwal J, Kotwal A, Mishra P, Dutta V, Chopra S. Correlation of haemoglobin and red cell indices with serum ferritin in Indian women in second and third trimester of pregnancy. Med J Armed Forces India. 2013;69(1):31-6.

10. Short MW, Domagalski JE. Iron deficiency anemia: evaluation and management. Am Fam Physician. 2013;87(2):98-04

11. Kriplani A, Mahey R, Dash BB, Kulshreshta V, Agarwal N, Bhatla N. Intravenous iron sucrose therapy for moderate to severe anaemia in pregnancy. Indian $J$ Med Res. 2013;138(1):78-82.

12. Guilherme de FF, Raphaela AM, Larissa C, Miriam DH, Rosiane LC. Structural and emulsifying properties of sodium caseinate and lactoferrin influenced by ultrasound process. Food Hydrocolloids. 2017;63:178-88.

13. Giansanti F, Panella G, Leboffe L, Antonini GI. Lactoferrin from Milk: Nutraceutica and Pharmacological Properties. Pharmaceuticals Basel. 2016;9(4):E61.
14. Abu Hashim H, Foda O, Ghayaty E. Lactoferrin or ferrous salts for iron deficiency anemia in pregnancy: A meta-analysis of randomized trials. Eur J Obstet Gynecol Reprod Biol. 2017;219:45-52

15. Rosa L, Cutone A, Lepanto MS, Paesano R, Valenti P. Lactoferrin: A Natural Glycoprotein Involved in Iron and Inflammatory Homeostasis. Int J Mol Sci. 2017;18(9):1985.

16. Paesano R, Pacifici E, Benedetti S, Berlutti F, Frioni A, Polimeni A, et al. Safety and efficacy of lactoferrin versus ferrous sulphate in curing iron deficiency and iron deficiency anaemia in hereditary thrombophilia pregnant women: An interventional study. Biometals. 2014;27(5):999-06.

17. Natik H. Duaa A. Hussein. The concentration of lactoferrin and its relationship with minerals and amino acids in cow's milk. Scientific Papers. Series D. Animal Science. Vol. LIX. 2016;59.

18. Mohamed R, Mohamed K, Ragab D, Abd-Elhamid S, Adel A. Oral lactoferrin versus ferrous sulphate and ferrous fumerate for the treatment of iron deficiency anemia during pregnancy. Journal of Advanced Nutrition and Human Metabolism. 2015;2:e740

19. Abu HH, Foda O, Ghayaty E. Lactoferrin or ferrous salts for iron deficiency anemia in pregnancy: A meta-analysis of randomized trials. Eur J Obstet Gyneco Reprod Biol. 2017;219:45-52.

20. Chandrakala K, Zahedabano, Meenakumari A. Comparative study of efficacy and safety of iron polymaltose complex with ferrous sulphate in antenatal women with moderate anemia. IOSR-JDMS. 2013;9:9-13.

21. Adamson JW. Iron deficiency and other hypoproliferative anemias. In: Braunwald E, Fauci AS, Kasper DL (Eds.). Harrison's Principles of Internal Medicine 17 $7^{\text {th }}$ Edition. New York: McGraw Hill. 2008:628-33.

22. Koikawa N, Nagaoka I, Yamaguchi M, Hamano H, Yamauchi K, Sawaki K. Preventive effect of lactoferrin intake on anemia in female long distance runners. Biosci Biotechnol Biochem. 2008;72(4):931-5.

23. Chow JK, Werner BG, Ruthazer R, Snydman DR. Increased serum iron levels and infectious complications after liver transplantation. Clin Infect Dis. 2010; $51(3): e 16-23$.

24. Maccio A, Madeddu C, Gramignano G, Mulas C, Sanna E, Mantovani G. Efficacy and safety of oral lactoferrin supplementation in combination with rHuEPO-beta for the treatment of anemia in advanced cancer patients undergoing chemotherapy: Open-label, randomized controlled study. Oncologist. 2010;15(8):894-902.

25. Tolkien Z, Stecher L, Mander AP, Pereira DI, Powell JJ. Ferrous sulfate supplementation causes significant gastrointestinal side-effects in adults: A systematic review and meta-analysis. PLoS One. 2015;10(2):e0117383.

Cite this article : Taruni R, Sivaraman M, Dutta T, Dhanasekar KR. A Comparative Study to Evaluate the Efficacy of Oral Lactoferrin Fortified Bovine Colostrum with Oral Iron in the Treatment of Iron Deficiency Anemia. Int J Med Public Health. 2018;8(2):65-70. 